\title{
Outdoor enthusiasts' perspectives on livestock animal treatment
}

Elizabeth S. Byrd

West Virginia University

Nicole J. Olynk Widmar

Purdue University

Recommended Citation

Byrd, E. S., \& Widmar, N. J. O. (2017). Outdoor enthusiasts' perspectives on livestock animal treatment. International Interdisciplinary Business-Economics Advancement Journal, 2(2), 81-94.

\section{Revisions}

Submission date: Dec. 19, 2016

1st Revision: Mar. 5, 2017

Acceptance: Jul. 10, 2017 


\title{
Outdoor Enthusiasts' Perspectives on Livestock Animal Treatment
}

\author{
Elizabeth S. Byrd ${ }^{1}$ and Nicole J. Olynk Widmar ${ }^{2}$ \\ Davis College of Agriculture, Natural Resources, and Design \\ West Virginia University, United States \\ 1ebyrd@mail.wvu.edu \\ Department of Agricultural Economics \\ Purdue University, United States \\ 2nwidmar@purdue.edu
}

\begin{abstract}
Demand for pork chops and chicken breasts were analyzed using best-worst scaling and consumer choice experiments. Outdoor enthusiasts (who regularly hunt, fish, or participate in outdoor activities), which represent a unique consumer group with respect to livestock animal welfare, were surveyed with respect to meat purchasing attributes. Six meat attributes were analyzed for relative levels of preferences with safety having the largest share. Nutrition and taste were more important to outdoor enthusiasts than a representative sample of U.S. residents. Positive and significant mean willingness to pay estimates were obtained with the exception of locally produced pork chops. Outdoor enthusiasts were willing to pay a higher amount for retailer and industry verified antibiotic free pork chops than a representative sample of U.S. consumers.
\end{abstract}

Keywords: best-worst scaling, livestock animals, willingness to pay

\section{Introduction and Review of Literature}

Consumers are concerned with the social, animal welfare, environmental, and food safety attributes of the production of the livestock-derived food products they consume (Olynk, Tonsor, $\&$ Wolf, 2010). Studies have documented consumer willingness to pay (WTP) for animal welfarerelated production process attributes such as hog production without gestation crates (Tonsor, Olynk, \& Wolf, 2009), egg production without battery cages (Lusk \& Norwood, 2011), milk production without rBST (Olynk \& Ortega, 2013), and beef production without the use of growth hormones (Dickinson \& Bailey, 2002). However, most studies are limited to general samples of US residents (Brooks \& Ellison, 2014; Lister, Tonsor, Brix, Schroeder, \& Yang, 2014; Lusk \& Parker, 2009) or residents of specific states (Tonsor et al., 2009). Similarly, Cummins, Widmar, Croney, \& Fulton (2016) utilized best worst scaling to explore the relative preferences for pork attributes including animal welfare in a nationally representative survey.

The meaning or interpretation of "good" animal welfare can differ from person to person. For example, farmers and veterinarians may assess the animal's body condition and access to feed, water, and shelter (Hewson, 2003). For others, good animal welfare implies the animal is allowed to perform its natural behaviors; conventional laying hen battery cages have been largely abandoned in favor of housing systems which provides hens with a perch to roost and a private area to lay eggs (Hewson, 2003). Farmers often have differing views on animal welfare from 
consumers (Te Velde, Aarts, \& Wan Woerkum, 2002; Tonsor, Wolf, \& McKendree, 2014). In addition, past research has linked pet ownership to increased concern for livestock welfare (McKendree, Croney \& Widmar, 2014a). Thus, relationships with animals, even those that are not consumed for food, can be related to consumers' level of concern for the management of livestock animals. Research has also focused on concern for wild or feral animals; studies have explored the public's acceptance of lethal management of wildlife in general (Dubois \& Harshaw, 2013; Koval $\&$ Mertig, 2004), lethal control of coyotes (Martínez-Espiñeira, 2006) and lethal control of feral cats (Loyd \& Miller, 2010).

\section{Outdoor Enthusiasts in the US}

Hunting has recently been the subject of several national headlines and in an age of social media, even local headlines can become national news. A Time Magazine cover story in December of 2013 directed increased attention to the management of wild species via hunting (Von Drehle, 2013). A teenage hunter made headlines when a public outcry resulted in her hunting photos being removed from Facebook (Perez, 2014). In Maine, an activist backed ballot initiative aimed at ending the use of dogs, traps, and bait in black bear hunts failed (USA Today, 2014). Further, it is reasonable to suspect that hunting and wildlife news may affect different groups uniquely.

In 2011, 13.7 million Americans hunted, spending 282 million days in the field and $\$ 33.7$ billion (U.S. Department of the Interior, U.S. Fish and Wildlife Service, and U.S. Department of Commerce, \& U.S. Census Bureau, 2014). Furthermore, from 2006 to 2011 the number of US residents over the age of 16 who hunted increased by 9\% (U.S. Dept. of the Interior et al., 2014). Hunters who resided in a metropolitan statistical area (MSA) made up the majority of hunters; only $20 \%$ of hunters resided outside of an MSA (U.S. Dept. of the Interior et. al, 2014). A total of 33.1 million anglers spend 554 million days fishing and spent 41.8 billion dollars (U.S. Dept. of the Interior et al., 2014).

For the purposes of this analysis, outdoor enthusiasts are individuals who self-described as having regularly participated in outdoor activities such as fishing, hunting, hiking, camping, and watching wildlife. According to the most recent National Survey of Fishing, Hunting, and WildlifeAssociated Recreation, 6\% of U.S. residents 16 and older participated in hunting; 14\% of U.S. residents of the same age category participated in fishing, and almost one third participated in wildlife watching (U.S. Dept. of the Interior et. al, 2014). In terms of the connectedness of people to their food, hunters and anglers may be similar to or even closer to their food than farmers. There are 13.7 million hunters in the U.S. (U.S. Dept. of the Interior et al., 2014), but only 3.2 million farmers operating farms in the U.S. (USDA, 2014). Thus, the population of hunters and anglers is substantial, but the perceptions of hunters and anglers with regard to livestock animal welfare are largely unstudied. The perceptions of outdoor enthusiasts with regard to livestock treatment and meat production are the main focus of this analysis.

This work fills a gap in knowledge by investigating how sentiments towards and interactions with wild animals, both consumptive and non-consumptive, may be related to the level of concern for the welfare of livestock species. This research explores how the underlying value system of outdoor enthusiasts informs meat purchasing decisions and WTP for verified pork chop and chicken breast attributes. This analysis determines how consumers' outdoor activities, demographic factors, and other factors such as pet ownership and opinions on hunting are related 
to the relative importance of meat attributes obtained from best-worst methodology and WTP for verified production process attributes for chicken breasts and pork chops. The primary research question is to determine whether self-reported outdoor enthusiasts have statistically different preferences for animal welfare (in general and specific attributes) than a nationally representative sample of U.S. residents. Understanding how involvement with outdoor activities and the demographics associated with different important levels of animal welfare and WTP for animal welfare attributes is of interest to food companies, marketers, and policy makers alike.

\section{Methods}

Best-worst scaling was utilized to determine the relative importance of general meat product attributes and a choice experiment was employed to determine the WTP for specific verified attributes. Online surveys were used to collect data from a sample of outdoor enthusiasts and a nationally representative sample. Specifically, the surveys focused on respondents' outdoor activities, socio-demographic characteristics, household characteristics and elicited the data necessary for the WTP and best-worst methodologies. A proprietary opt-in database (Lightspeed GMI) was used to identify and contact potential survey respondents. Respondents contacted by the panel provider were screened by the researchers for fit within the sample; fit was determined by being over 18 years of age and self-reported active participation in either hunting, fishing, and/or hiking, camping, or other outdoor activities. The survey was hosted on Qualtrics.

A total of 872 outdoor enthusiasts completed the survey. In order to participate in the survey, respondents had to first indicate they were 18 years of age or older. In addition, respondents were then asked if they regularly participated in fishing, hunting, or other outdoor activities like camping or hiking (they were permitted to select more than one activity). Only those who indicated they regularly participated in these activities were permitted to continue with the survey. A second, nationally representative survey $(n=825)$ was also conducted with the same best-worst scaling and choice experiment questions, to facilitate comparison.

\section{Econometric Analysis: Best-Worst Scaling}

Respondents were presented with a choice experiment using a modified best-worst scaling to assess their relative preferences for six meat value attributes: taste, convenience, safety, animal welfare, price, and nutrition. Best-worst scaling is superior to Likert scaling because it forces respondents to make tradeoffs between items (Sackett, Shupp, \& Tonsor, 2013). For each bestworst task in this analysis, respondents were shown a pair of meat attributes and asked to choose the attribute that was most important (best) to them. From their choice of the most important attribute, the remaining attribute was inferred to be the least important (worst), following Holland, Widmar, Widmar, Ortega, \& Gunderson (2014). Survey participants were shown a total of 15 bestworst choice experiment tasks. These were blocked into three blocks of five best-worst tasks spaced approximately equally throughout the survey to help prevent fatigue with the best-worst task.

Each attribute could potentially be selected by each respondent between zero and five times in the experimental design. The respondents' choices of the best and worst attributes were used to determine each attribute place along a continuum of importance when purchasing meat (Lusk \& Briggeman, 2009). A total of 6 attributes, $j$, were investigated through the use of best-worst methodology; therefore there are a total of $J *(J-1)=30$ potential combinations of best-worst 
rankings that could have been chosen by each respondent. The location of the value attribute on the scale of importance for meat purchasing is represented by $\lambda_{j}$. Thus, the level of importance, which is unobservable to researchers, for consumer $i$ is:

$I_{i j}=\lambda_{i}+\varepsilon_{i j}$

where $\varepsilon_{i j}$ represents a random error term. The probability that the consumer $i$ chooses attribute $j$ as the best option and attribute $k$ as the worst option is the probability that the difference between $I_{i j}$ and $I_{i k}$ is greater than all $J *(J-1)-1=29$ potential differences available from the choices show to each respondent. The error term is assumed to be independently and identically distributed type I extreme value. Following Lusk and Briggeman (2009) the probability of choosing a given best-worst combination takes the form represented by:

$\operatorname{Prob}(j=$ best $\cap k=$ worst $)=\frac{e^{\lambda_{j}-\lambda_{k}}}{\sum_{l=1}^{J} \sum_{m=1}^{J} e^{\lambda_{l} \lambda_{m}-J}}$

Maximum likelihood estimation (MLE) is then used to estimate the parameter $\lambda_{j}$ which represents how important attribute $j$ is relative to the least important attribute. The least important attribute is not known ex ante, but is determined through analysis of the respondent's answers and its value must be normalized to zero to prevent issues with dummy variables (Lusk \& Briggeman 2009).

Following Lusk and Briggeman (2009) and Cummins et al. (2016) a random parameters logit (RPL) model was used to allow for heterogeneity among individuals. The RPL models estimated in this analysis were completed using NLogit 5.0. The resulting preference shares, which must necessarily sum to one across all six attributes, can be calculated as (Lusk \& Briggeman, 2009):

$\operatorname{share~}_{j}=\frac{e^{\lambda_{j}}}{\sum_{k=1}^{J} e^{\lambda_{l}}}$

Individual preference shares are calculated using individual-specific estimates from the RPL model. Individual-specific preference shares can be used to analyze the correlations between one's preference shares and demographic or other factors of interest, such as the respondent's outdoor activities or opinions on hunting practices.

\section{Econometric Analysis: Willingness to Pay}

In addition to best-worst scaling tasks, respondents were randomly assigned to a choice experiment for either pork chops or chicken breasts. For the pork chop choice experiment, respondents received information about whether individual crates/stalls were permitted or not permitted (Crate), location was local or no claim was made (Local), and whether antibiotic use was permitted or not permitted (Anti). For the chicken breast choice experiment, respondents were shown information about whether pasture access was required or not required, location was local or no claim was made, and whether antibiotic use was permitted for not permitted. For each product, information about whether the certification entity was the USDA Process Verified Program (USDA-PVP), a retailer, or an industry (pork or poultry) group was provided. Respondents were 
shown three price levels for each product in dollars per pound. Pork chops were offered at $\$ 2.49 / \mathrm{lb}$., $\$ 3.89 / \mathrm{lb}$., and $\$ 5.29 / \mathrm{lb}$. Chicken breasts were offered at $\$ 1.89 / \mathrm{lb}$., $\$ 3.15 / \mathrm{lb}$, and $\$ 4.41 / \mathrm{lb}$. The prices shown were comparable to the range of retail prices for pork chops and chicken breasts at the time of survey administration according to the USDA Weekly Retail Chicken and Pork Feature Activity Publications which reports a national average price and price ranges for different regions of the country.

To determine the choice scenarios shown to respondents, the SAS OPTEX program was used to create the main effects plus two-way interaction experimental design (Lusk \& Norwood, 2005) which maximized the D-efficiency at 86.84. This design yielded a total of 24 choice sets for each product which were divided into three blocks so that respondents were shown eight choice sets in total (Olynk \& Ortega, 2013; Tonsor, Schroeder, Fox, \& Biere, 2005). As a part of the choice experiment, a "cheap talk" strategy was utilized to reduce hypothetical bias where researchers inform respondents of potential bias before they take part in the choice experiment (Lusk, 2003).

Choice experiments rely on random utility theory. In the random utility model employed to analyze the resulting data, utility is composed of a deterministic component $V_{\text {nit }}$, which depends on the attributes of an alternative, and a stochastic component, $\varepsilon_{n i t}$, as:

$U_{n i t}=V_{n i t}+\varepsilon_{\text {nit }}$

Respondent $n$ will choose alternative $i$ if $U_{\text {nit }}>U_{n j t} \forall j \neq i$. The probability of respondent $n$ choosing alternative $i$ can be represented by:

$P_{n i t}=\operatorname{Prob}\left(V_{n i t}+\varepsilon_{n i t}>V_{n j t}+\varepsilon_{n j t} ; \forall j \in C, \forall j \neq i\right)$

Given the assumed underlying distribution of the error term, the closed form of the logit choice probability can be expressed as:

$P_{\text {nit }}=\frac{\exp \left(V_{\text {nit }}\right)}{\sum_{j} \exp \left(V_{n j t}\right)}$

Utilizing a model that allows for heterogeneous preferences is appropriate because previous research suggests that consumers preferences are heterogeneous (Alfnes, 2004; Lusk, Roosen, \& Fox, 2003; Tonsor et al., 2005). Thus, a random parameters logit (RPL) model was employed.

If we employ the simplifying assumption that the deterministic portion, $V_{\text {nit }}$, is linear in its parameters, the general model can be specified as:

$V_{i t}=\beta_{1} x_{i t}+\cdots+\beta_{k} x_{i t}$

where $x_{i t}$ is the vector of attributes associated with the $i^{\text {th }}$ alternative, and the $\beta^{\prime} s$ are the parameters associated with those attributes. For pork chops the model for the deterministic part of utility, $v$, for individual $i$, can be expressed as: 


$$
\begin{aligned}
v_{i}= & \beta_{1} \text { Price }_{i}+\beta_{2} \text { USDA_Crate } A_{i}+\beta_{3} \text { Retailer_Crate }_{i}+ \\
& \beta_{4} \text { Industry_Crate }_{i}+\beta_{5} U S D A_{-} \text {Loc }_{i}+\beta_{6} \text { Retailer }_{-} \text {Loc }_{i}+\beta_{7} \text { Industry }_{-} \text {Loc }_{i}+ \\
& \beta_{8} \text { USDA_Ant } i_{i}+\beta_{9} \text { Retailer_Anti }_{i}+\beta_{10} \text { Industry_Anti }_{i}+\beta_{11} \text { OptOut }_{i}
\end{aligned}
$$

where Price $_{i}$ is the price of the boneless, center-cut pork chop and OptOut ${ }_{i}$ is a constant representing the negative utility of not having the pork chop in the choice set. The terms, such as $\beta_{2} U S D A_{-}$Crate $_{i}$ are effects-coded interaction terms between the attributes, in this case individual crates/stalls, and the verification agency. Following Olynk et al. (2010) an example interpretation of the interaction terms between an attribute and a verification agency is the WTP for the USDA to verify crate free production as opposed to not having the USDA verify crate free production. Effects coding is used to avoid confounding effects of absence of attributes with the "no purchase" option. Whereas regular dummy variables are coded 0 or 1 , effects coding takes on the values 0 , 1 , or -1 . The attribute is given a value of 1 when the attribute is present, -1 when the base category or the attribute is not present, and 0 otherwise (Tonsor et al., 2009). Attributes were not included without being interacted with a verification agency. By the design of the choice experiment respondents never considered attributes without a verification agency. This is consistent with the real world in that products with animal welfare claims are unlikely to be marketed without a verification or certification. (Olynk et al., 2010). To estimate mean WTP estimates, the standard equation was used; for example, the WTP equation for USDA verified crate free production was:

$W T P_{k}=-2\left(\frac{\beta_{2}}{\beta_{1}}\right)$

The coefficients, the $\beta^{\prime} s$, on all variables except Price are assumed to vary normally across consumers and are drawn from a normal distribution to allow for both positive and negative WTP estimates (Lusk et al, 2003; Tonsor et al., 2005). A standard logit model exhibits independence from irrelevant alternatives; RPL models do not. Revelt and Train (1998) identified the possibility for correlated taste parameters to form general patterns. To gain a better understanding these potential correlations, Revelt and Train (1998) suggest constructing a Cholesky matrix $\Omega$. Allow $\boldsymbol{\beta}$ to be a $k x 1$ vector of the coefficients on the attributes and $\boldsymbol{\eta}$ a $(k-2) x 1$ vector of coefficients on random attributes in $\boldsymbol{\beta}$. Then specify $\boldsymbol{\eta} \sim N(\bar{\eta}, \Omega)$. The result can be expressed as $\boldsymbol{\eta}=\bar{\eta}+L \boldsymbol{M}$ where $\mathrm{L}$ is the lower triangular Cholesky factor such that $L L^{\prime}=\Omega$. Following Revelt \& Train (1998), The M-vector contains independent normal deviates. Estimates of the Cholesky matrix exhibiting statistical significance supports interdependence in tastes and of potential correlations in preferences across attributes in the choice set (Scarpa \& Del Guidice, 2004).

Confidence intervals for WTP point estimates were found using the Krinsky-Robb method (Krinsky \& Robb, 1986). Hole (2007) found the delta, Fieller, Krinsky-Robb and bootstrapping methods to construct confidence intervals for WTP estimates yield similar results. Statistical comparisons between the preference shares for each best-worst experimental design and WTP results from the choice experiment was conducted following the complete combinatorial method proposed by Poe, Giraud, and Loomis (2005).

\section{Findings}

Demographics of the outdoor enthusiast and national representative surveys are presented in Table 1. A total of 872 respondents completed the outdoor enthusiast survey. This sample was comprised of $50 \%$ male and $50 \%$ female respondents; the mean age of respondents was 47 years. After 
converting household income to be a continuous variable, the average or mean household income was calculated at $\$ 59,495$ which was slightly higher than the U.S. median household income of $\$ 53,046$ (U.S. Census Bureau, 2014). In addition to having a higher median household income, this sample is slightly more educated than the population. In this sample, $99 \%$ of respondents graduated high school and $42 \%$ had completed at least 4 years of college. According to the census, $85.7 \%$ of American over 25 years of age have graduated high school, and $28.5 \%$ of respondents have a bachelor's degree or higher (U.S. Census Bureau, 2014). The mean household size in this sample is 2.62 people which is nearly identical to the U.S. average of 2.61 (U.S. Census Bureau, 2014).

The outdoor enthusiast sample was compared to a nationally representative US sample. Because the sample was recruited to include outdoor enthusiasts, it contains more respondents that hunt and fish than the national average; in the U.S., $6 \%$ of residents hunt and $14 \%$ fish (U.S. Department of the Interior et al., 2014). In this sample of U.S. consumers, 63\% regularly participated in fishing, $27 \%$ regularly participated in hunting, and $79 \%$ regularly participated in other outdoor activities. The nationally representative sample contained 825 respondents and was similar in age, income, region of residence, and education to the outdoor enthusiast sample (Table 1). In the nationally representative sample, 24\% participated in fishing, 10\% reported participating in hunting, and 36 $\%$ reported participating in other outdoor activities.

Opinions regarding hunting, not just participation in hunting are hypothesized to be related to concern for livestock animal welfare. Therefore, respondents were asked if they felt hunting for food and hunting for a trophy were acceptable reasons for others to hunt. Consistent with previous studies, 93\% of respondents agreed with obtaining food as a reason for hunting (Duda, Jones, \& Criscione, 2010; Heberlein \& Willebrand 1998). Meanwhile, only 33\% agreed with trophy hunting as a reason for hunting.

\section{Best-Worst Scaling}

The perceptions of outdoor enthusiasts, in particular those who regularly participate in hunting activities, are of interest in this analysis because it is hypothesized that hunters, being involved in the process of harvesting and processing wild animals, may have differing views with respect to meat and animal welfare. Analysis of the best-worst tasks revealed safety was the attribute with the largest preference share at $23.0 \%$, followed by taste at $20.2 \%$, nutrition at $17.7 \%$, animal welfare at $16.3 \%$, price at $14.1 \%$, and finally convenience with $8.7 \%$ of the preference share. Lusk and Briggeman (2009) also found that safety was the most important attribute among a set of eleven food values for organic foods. Likewise, Lusk and Parker (2009) found that safety was the most important factor when ground beef was studied followed by expiration date which the authors argue is also related to food safety. 
Table 1: Respondent Demographics

\begin{tabular}{lll}
\hline Demographic Variable & Percentage (\%) of Respondents \\
\hline Male & $\begin{array}{l}\text { Outdoor Enthusiast } \\
\text { Sample n=872 }\end{array}$ & $\begin{array}{l}\text { Nationally Representative } \\
\text { Sample n=825 }\end{array}$ \\
Age & 50 & 49 \\
18-24 & 7 & 13 \\
$25-44$ & 38 & 34 \\
45-64 & 38 & 34 \\
65+ & 18 & 19 \\
Education & 1 & \\
Did not graduate from high school & 21 & 3 \\
Graduated from high school, Did not attend & & 22 \\
college & 21 & \\
Attended College, No Degree Earned & 14 & 26 \\
Attended College, Associates or Trade Degree & 29 & 15 \\
Attended College, Bachelor's Degree Earned & 23 \\
Graduate or Advanced Degree (M.S., PhD., Law & 13 & 10 \\
School) & & \\
Annual Household Pretax Income & 14 & 19 \\
Less than \$20,000 & 22 & 29 \\
\$20,000 - \$39,999 & 21 & 23 \\
\$40,000 - \$59,999 & 17 & 12 \\
\$60,000-\$79,999 & 10 & 7 \\
\$80,000-\$99,999 & 6 & 3 \\
\$100,000-\$119,999 & 11 & 6 \\
\$120,000 or more & & \\
Region & 17 & 17 \\
Northeast & 33 & 33 \\
South & 26 & 27 \\
Midwest & 25 & 36 \\
West & 63 & \\
Outdoor Activities Regularly Participated in & 27 & \\
Fishing & 79 & \\
Hunting & & \\
Other & & \\
& & \\
\hline
\end{tabular}

Table 2 shows the mean share estimates and 95\% confidence intervals calculated using the Krinsky-Robb method. A table of coefficients and standard deviations is available from the authors on request. Individual-specific shares were calculated using individual-specific parameter estimates and were utilized for all calculations and correlations throughout this analysis. Reporting gender as female was correlated with having smaller preference shares for price $(r=-.13, p<.01)$, convenience $(r=-.19, p<.01)$, taste $(r=-.18, p<.01)$, and nutrition $(r=-.18, p<.01)$, but a larger preference share for animal welfare $(r=.18, p<.01)$. Previous research has also found that women were more likely to report concern about animal welfare in general (McKendree et al., 2014a) and that women were less supportive of lethal means of wildlife management (Koval \& Mertig, 2004). Likewise, Loyd and Miller (2010) found that women were less likely to prefer euthanasia of feral cats than men. 
Table 2: Best-Worst Scaling Random Parameters Logit Results

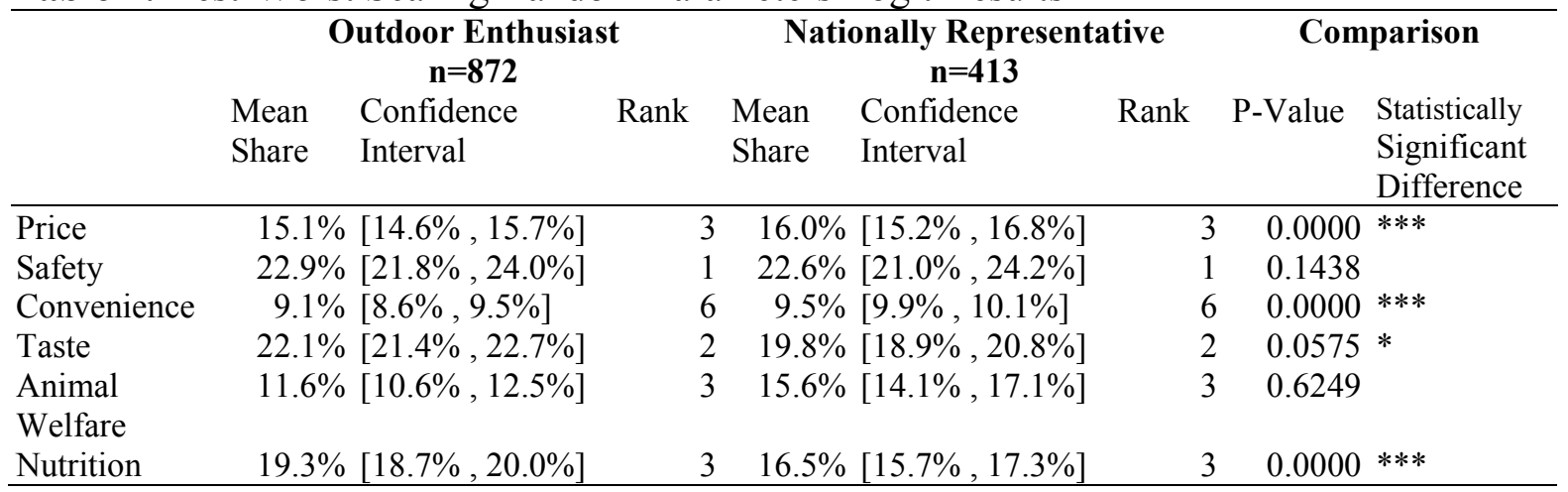

Notes: Statistical significance to the $1 \% \%^{* *}, 5 \% * *$, and $10 \% *$ levels.

Seventy percent of outdoor enthusiast respondents reported owning at least one dog or cat. Pet ownership (households having at least one cat or dog) was correlated with smaller preference shares devoted to price $(r=-.13, p<.01)$, convenience $(r=-.07, p<.05)$, taste $(r=-.14, p<.01)$, and nutrition $(r=-.14, p<.01)$ and a larger share for animal welfare $(r=.15, p<.01)$. This finding was consistent with McKendree, Croney, and Widmar (2014b) who found that pet ownership is positively related to reporting concern about animal welfare. Similarly, Martínez-Espiñeira (2006) found that cat ownership decreased the likelihood of approving of lethal methods of coyote control. Rothgerber and Mican (2014) found that childhood pet ownership was associated with higher levels of connection to and empathy for animals, but childhood ownership of pets was not associated with the decision not to eat animals (i.e. be strict vegetarians).

Other demographic factors were also explored for relationships with best-worst preference shares including respondents' participation in outdoor activities and approval for reasons people hunt. Identifying oneself as regularly fishing was positively correlated with the size of the mean shares of preference for convenience $(r=.13, p<.01)$, taste $(r=.11, p<.05)$, and nutrition $(r=.10, p<.01)$ and negatively correlated with the share attributed to animal welfare $(r=-.09, p<.01)$. Regularly hunting was positively correlated with the size of the preference shares allocated to convenience $(r=.11$, $p<.05)$ and nutrition $(r=.08, p<.05)$, but negatively correlated with the preference share devoted to safety $(r=-.08, p<.05)$. Agreeing that hunting to obtain food was acceptable was positively correlated with a higher preference shares for taste $(r=-.10, p<.01)$ and nutrition $(r=-.10, p<.01)$, but a lower share devoted to animal welfare $(r=-.11, p<.01)$. Likewise, agreeing that hunting for a trophy animal was acceptable was positively correlated with higher preference shares for price $(r=.11, p<.01)$, convenience $(r=.22, p<.01)$, taste $(r=.18, p<.01)$, and nutrition $(r=.18, p<.01)$ and a lower share for animal welfare $(r=-.17, p<.01)$. It is hypothesized that hunters, and those who agree with hunting as a means for obtaining food, may exhibit less concern for animal welfare and thus tend to have a (relatively) lower preference share devoted to animal welfare. Previous research found that animal producers are less concerned about animal welfare than consumers (Te Velde et al., 2002) and producers and consumers do not see eye to eye on animal welfare issues (Tonsor et al., 2014). More specific to wildlife, the public and wildlife agency employees have been found to have differing levels of support for lethal management of wildlife (Koval \& Mertig, 2004).

A statistical comparison between the preference shares for each best-worst experimental design and WTP results from the choice experiment was conducted following the complete combinatorial 
method proposed by Poe et al. (2005). The results of the best-worst analysis from the nationally representative sample and comparison between the two samples is shown in Table 2. The two samples have similar rankings when the confidence intervals are examined via the method of overlapping confidence intervals. However, outdoor enthusiasts have statistically different (higher) distributions of preference shares for taste and nutrition and statistically different (lower) preference shares for price and convenience.

\section{Willingness to Pay}

A hypothetical shopping scenario forces respondents to make tradeoffs among different products, or bundles of attributes. Table 3 reports the WTP estimates for pork chops and chicken breasts. A modified RPL model which accounted for whether respondents self-reported regularly hunting or not was investigated. However, WTP estimates did not differ between these groups for all but the WTP estimates for chicken breasts with pasture access verified by either the USDA or poultry industry. Thus, the parameter estimates and standard deviation estimates for both pork chops and chicken breasts for the model modified to account for whether the respondent self-reported regularly hunting or not were omitted for brevity. The parameter estimates are available from the authors upon request. The mean estimates for WTP for most verified attributes for both pork chops and chicken breasts were positive with the exception of locally produced pork chops. Thus, with respect to verified local production, consumers appear to view pork chops and chicken breasts differently. This finding is consistent with Olynk et al. (2010) who found that WTP for verified attributes differed across livestock species and attribute when pork chops and milk were considered.

Previous research has considered the size of potential market as an important outcome of consumer demand work. Olynk et al. (2010) calculated the percentage of consumers WTP above a threshold level to assist producers in determining the potential market share for their products and identified critical points at which point producers should switch verification agencies. In similar fashion, the percentage of hunters and non-hunters that are WTP a positive amount for locally produced chicken breasts and pork chops was calculated and the results are shown in Figure 1. Interestingly, a higher percentage of non-hunters are willing to pay a positive amount for local chicken breasts verified by a retailer or the USDA. On the other hand, a higher percentage of hunters are willing to pay for locally produced pork chops verified by all sources. It is important that livestock producers recognize that the proportion of the market (or portion of consumers) with positive WTP for locally produced meat varies depending on the species, and perhaps product, in question.

Table 3 reports the mean WTP estimates, 95\% confidence intervals, and results of the complete combinatorial test proposed by Poe et al., (2005) comparing distributions of WTP results. There were no statistical differences between the outdoor enthusiast and nationally representative WTP estimates for chicken breasts. For pork chops statistically significant differences in the distributions of the WTP estimates were noted for retailer verified antibiotic use, industry verified antibiotic use, and industry verified local production. For antibiotic free production, outdoor enthusiasts had a statistically higher WTP than the nationally representative sample. For industry verified local production, outdoor enthusiasts had a statistically less negative WTP than the nationwide sample. 
Table 3. Mean Marginal WTP Results With 95\% Confidence Intervals

\begin{tabular}{|c|c|c|c|c|c|c|}
\hline \multicolumn{7}{|c|}{$\begin{array}{l}\text { Pork Chops } \\
\end{array}$} \\
\hline & \multicolumn{2}{|c|}{$\begin{array}{c}\text { Outdoor Enthusiast } \\
\mathrm{n}=435\end{array}$} & \multicolumn{2}{|c|}{$\begin{array}{l}\text { Nationally Representative } \\
\qquad \mathrm{n}=413\end{array}$} & \multicolumn{2}{|c|}{ Comparison } \\
\hline & WTP & $\begin{array}{c}\text { Confidence } \\
\text { Interval }\end{array}$ & WTP & $\begin{array}{c}\text { Confidence } \\
\text { Interval }\end{array}$ & P-value & $\begin{array}{r}\text { Statistical } \\
\text { Significance }\end{array}$ \\
\hline Opting Out & $\$(8.78)$ & {$[-\$ 13.46,-\$ 5.25]$} & $\$(5.53)$ & {$[-\$ 7.51,-\$ 3.57]$} & 0.9376 & \\
\hline Individual Crate_USDA & $\$ 2.29$ & {$[\$ 1.35, \$ 3.59]$} & $\$ 2.09$ & {$[\$ 1.05, \$ 3.19]$} & 0.4078 & \\
\hline $\begin{array}{l}\text { Individual } \\
\text { Crate_Retailer }\end{array}$ & $\$ 0.87$ & {$[-\$ 0.25, \$ 2.19]$} & $\$ 0.09$ & {$[-\$ 0.79, \$ 1.02]$} & 0.1447 & \\
\hline $\begin{array}{l}\text { Individual Crate_Pork } \\
\text { Industry }\end{array}$ & $\$ 0.28$ & {$[-\$ 1.12, \$ 2.04]$} & $\$ 2.57$ & {$[\$ 0.45, \$ 4.82]$} & 0.9618 & \\
\hline AntibioticUse_USDA & $\$ 3.65$ & {$[\$ 2.74, \$ 4.84]$} & $\$ 4.51$ & {$[\$ 3.37, \$ 5.92]$} & 0.8662 & \\
\hline AntibioticUse_Retailer & $\$ 3.55$ & {$[\$ 1.37, \$ 6.28]$} & $\$ 1.29$ & {$[\$ 0.16, \$ 2.57]$} & 0.0376 & $* *$ \\
\hline AntibioticUse_Industry & $\$ 3.81$ & {$[\$ 1.83, \$ 5.64]$} & $\$ 0.92$ & {$[-\$ 2.35, \$ 4.12]$} & 0.0648 & * \\
\hline Local_USDA & $\$(1.04)$ & {$[-\$ 2.82, \$ 0.45]$} & $\$(1.43)$ & {$[-\$ 2.40,-\$ 0.15]$} & 0.3512 & \\
\hline Local Retailer & $\$(2.57)$ & {$[-\$ 4.16,-\$ 1.25]$} & $\$(0.93)$ & {$[-\$ 1.99, \$ 0.00]$} & 0.9669 & \\
\hline Local_Industry & $\$(1.54)$ & {$[-\$ 3.28,-\$ 0.38]$} & $\$(3.46)$ & {$[-\$ 5.24,-\$ 1.99]$} & 0.0460 & ** \\
\hline \multicolumn{7}{|c|}{ Chicken Breast } \\
\hline & \multicolumn{2}{|c|}{$\begin{array}{l}\text { Outdoor Enthusiast } \\
\qquad n=437\end{array}$} & \multicolumn{2}{|c|}{$\begin{array}{l}\text { Nationally Representative } \\
\qquad \mathrm{n}=412\end{array}$} & \multicolumn{2}{|c|}{ Comparison } \\
\hline & WTP & $\begin{array}{c}\text { Confidence } \\
\text { Interval } \\
\end{array}$ & WTP & $\begin{array}{c}\text { Confidence } \\
\text { Interval }\end{array}$ & P-value & $\begin{array}{c}\text { Statistical } \\
\text { Significance }\end{array}$ \\
\hline Opting Out & $\$(8.41)$ & {$[-\$ 9.38,-\$ 7.59]$} & $\$(7.42)$ & {$[-\$ 8.25,-\$ 6.73]$} & 0.9527 & \\
\hline Pasture Access_USDA & $\$ 1.98$ & {$[\$ 1.50, \$ 2.54]$} & $\$ 1.85$ & {$[\$ 1.40, \$ 2.36]$} & 0.3523 & \\
\hline Pasture Access_Retailer & $\$ 1.52$ & {$[\$ 1.07, \$ 2.01]$} & $\$ 1.47$ & {$[\$ 0.95, \$ 1.98]$} & 0.4421 & \\
\hline $\begin{array}{l}\text { Pasture Access } \\
\text { _Industry }\end{array}$ & $\$ 1.37$ & {$[\$ 0.63, \$ 2.12]$} & $\$ 1.40$ & {$[\$ 0.85, \$ 1.99]$} & 0.5278 & \\
\hline AntibioticUse_USDA & $\$ 1.69$ & {$[\$ 1.28, \$ 2.14]$} & $\$ 1.58$ & {$[\$ 1.09, \$ 2.17]$} & 0.4073 & \\
\hline AntibioticUse_Retailer & $\$ 1.61$ & {$[\$ 1.11, \$ 2.19]$} & $\$ 1.28$ & {$[\$ 0.65, \$ 1.94]$} & 0.2276 & \\
\hline AntibioticUse_Industry & $\$ 1.55$ & {$[\$ 0.87, \$ 2.29]$} & $\$ 1.21$ & {$[\$ 0.54, \$ 1.91]$} & 0.2505 & \\
\hline Local_USDA & $\$ 1.83$ & {$[\$ 1.43, \$ 2.27]$} & $\$ 2.02$ & {$[\$ 1.58, \$ 2.51]$} & 0.7408 & \\
\hline Local_Retailer & $\$ 0.70$ & {$[\$ 0.29, \$ 1.08]$} & $\$ 0.33$ & {$[-\$ 0.23, \$ 0.87]$} & 0.1360 & \\
\hline Local Industry & $\$ 0.20$ & {$[-\$ 0.28, \$ 0.66]$} & $\$ 0.37$ & {$[-\$ 0.22, \$ 0.94]$} & 0.6517 & \\
\hline
\end{tabular}

Notes: Statistical significance to the $1 \%{ }^{* * *}, 5 \% * *$, and $10 \% *$ levels.

\section{Conclusions}

It has been previously shown that livestock producers view some animal welfare issues differently than consumers. It was hypothesized that hunters, who are often hands-on in the processing of meat, and those who agree with hunting as a means for obtaining food, may exhibit less concern for animal welfare than those not involved with or approving of hunting. Safety and taste were the most important attributes identified for outdoor enthusiasts and price and convenience were the least important. Reporting be female or a pet owner was correlated with a higher preference share devoted to animal welfare. On the other hand, reporting approval of hunting for food, regardless of their participation in hunting, was correlated with having a lower preference share for animal welfare. Outdoor enthusiasts placed relative less importance on price and convenience that a representative sample of U.S. consumers, but relative more importance on nutrition. However, the importance placed on animal welfare by the two samples was not statistically different. 


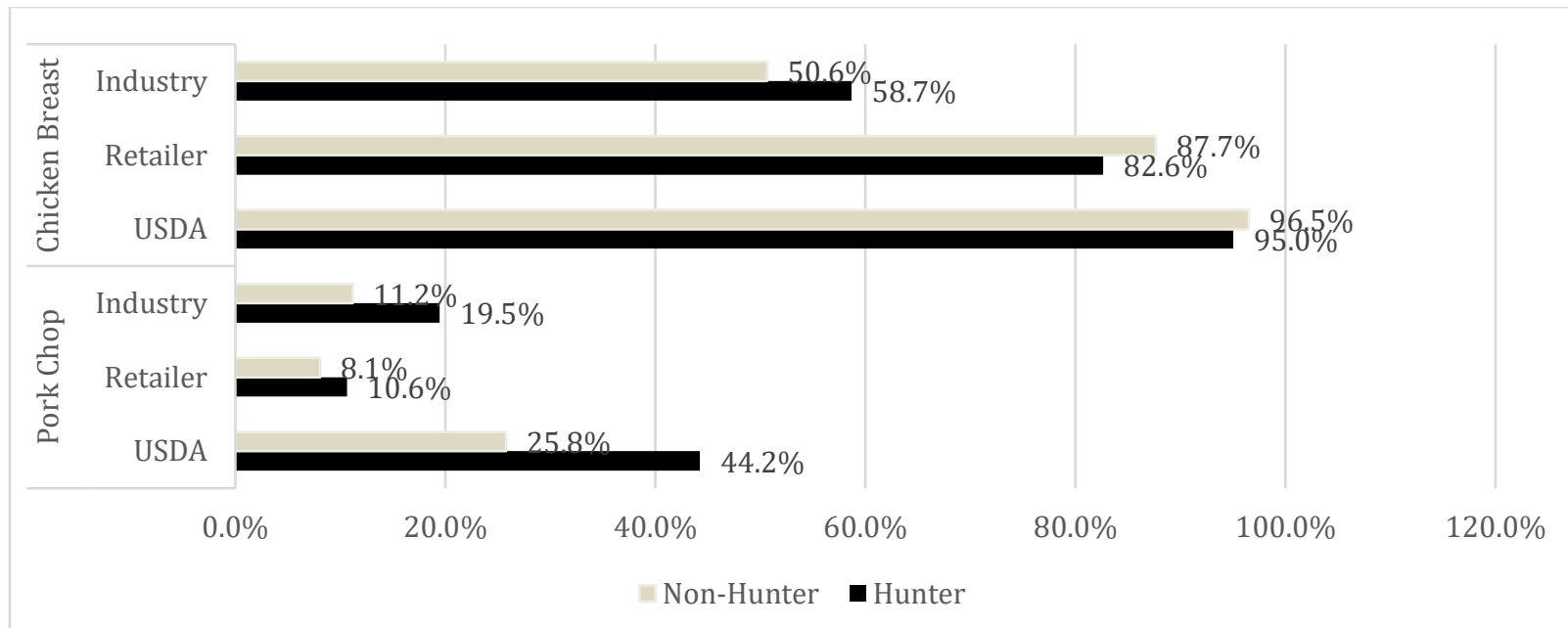

Figure 1. Percentage of outdoor enthusiasts WTP a positive amount for verified local production for pork chops and chicken breasts

This study contributes to the current body of knowledge regarding the factors and demographics that affect sentiments towards animal welfare related production process attributes of in meat. A simulated shopping scenario elicited the WTP for verified attributes for both pork chops and chicken breasts. The WTP for each attribute was positive with the exception of locally produced pork chops. A higher percentage of non-hunters were willing to pay a positive amount for local chicken breasts whereas a higher percentage of hunters were willing to pay for locally produced pork chops. Thus, proportion of the market WTP a positive amount for locally produced meat may vary depending on the species or product in question. However, outdoor enthusiasts only differed from the nationally representative sample in that outdoor enthusiasts were WTP more for antibiotic free pork from a single verification agency. Food companies and marketers should consider the proportion of the U.S. population that included outdoor enthusiasts before considering efforts that target these types of consumers.

\section{References}

Alfnes, F. (2004). Stated preferences for imported and hormone-treated beef: Application of a mixed logit model. European Review of Agricultural Economics, 31(1), 19-37.

Brooks, K., \& Ellison, B. (2014, July). Which livestock production methods matter most to consumers? Paper presented at the Agricultural \& Applied Economics Association's 2014 AAEA Annual Meeting, Minneapolis, MN.

Cummins, A. M., Widmar, N. J. O., Croney, C. C., \& Fulton, J. R. (2016). Understanding consumer pork attribute preferences. Theoretical Economics Letters, 6(2), 166-177.

Dickinson, D. L., \& Bailey, D. (2002). Meat traceability: Are US consumers willing to pay for it? Journal of Agricultural and Resource Economics, 27(2), 348-364.

Dubois, S., \& Harshaw, H. W. (2013). Exploring "humane" dimensions of wildlife. Human Dimensions of Wildlife, 18(1), 1-19.

Duda, M. D., M. F. Jones, \& Criscione, A. (2010). Sportsman's voice: Hunting and fishing in America. State College, PA: Venture.

Heberlein, T. A., \& Willebrand, T. (1998). Attitudes toward hunting across time and continents: The United States and Sweden. Gibier Faune Sauvage, 15, 1071-1080.

Hewson, C. J. (2003). What is animal welfare? Common definitions and their practical consequences. The Canadian Veterinary Journal, 44(6), 496-499. 
Hole, A. (2007). A Comparison of approaches to estimating confidence intervals for willingness to pay measures. Health Economics, 16(8), 827-840.

Holland, J., Widmar, N., Widmar, D., Ortega, D., \& Gunderson, M. (2014, February). Understanding producer strategies: Identifying key success factors of commercial farms in 2013. Paper presented at the Southern Agricultural Economics Association 2014 Annual Meeting, Dallas, TX.

Koval, M. H., \& Mertig, A. G. (2004). Attitudes of the Michigan public and wildlife agency personnel toward lethal wildlife management. Wildlife Society Bulletin. 32(1), 232-243.

Krinsky, I., Robb, A. L. (1986). On approximating the statistical properties of elasticities. The Review of Economics and Statistics, 68(4), 715-719.

Lister, G., Tonsor, G., Brix, M., Schroeder, T., \& Yang, C. (2014). Food values applied to livestock products. Retrieved from http://www.agmanager.info/livestock/marketing/WorkingPapers/WP1_FoodValuesLivestockProducts.pdf

Loyd, K. A. T., \& Miller, C. A. (2010). Influence of demographics, experience and value orientations on preferences for lethal management of feral cats. Human Dimensions of Wildlife, 15(4), 262-273.

Lusk, J. L. (2003). Effects of cheap talk on consumer willingness-to-pay for golden rice. American Journal of Agricultural Economics, 85(4), 840-856.

Lusk, J. L., \& Briggeman, B. C. (2009). Food values. American Journal of Agricultural Economics, 91(1), 184-196.

Lusk, J. L., \& Norwood, F. B. (2005). Effect of experimental design on choice-based conjoint valuation estimates. American Journal of Agricultural Economics, 87(3),771-785.

Lusk, J. L., \& Norwood, F. B. (2011). Speciesism, altruism and the economics of animal welfare. European Review of Agricultural Economics, 39(2),189-212.

Lusk, J. L., \& Parker, N. (2009). Consumer preferences for amount and type of fat in ground beef. Journal of Agricultural and Applied Economics, 41(1), 75-90.

Lusk, J. L., Roosen, J., \& Fox, J. (2003). Demand for beef from cattle administered growth hormones or fed genetically modified corn: A comparison of consumers in France, Germany, the United Kingdom, and the United States. American Journal of Agricultural Economics, 85(1),16-29. doi.org/10.1111/14678276.00100

Martínez-Espiñeira, R. (2006). Public attitudes toward lethal coyote control. Human Dimensions of Wildlife, $11(2), 89-100$.

McKendree, M. G. S., Croney, C. C., \& Widmar, N. J. O. (2014a). Effects of demographic factors and information sources on United States consumer perceptions of animal welfare. Journal of Animal Science, 92(7), 3161-3173.

McKendree, M. S., Croney, C. C., \& Widmar, N. O. (2014b). Bioethics symposium II: Current factors influencing perceptions of animals and their welfare. Journal of Animal Science, 92(5), 1821-1831. doi.org/10.2527/jas.2014-7586

Olynk, N. J., \& Ortega, D. L. (2013). Consumer preferences for verified dairy cattle management practices in processed dairy products. Food Control, 30(1), 298-305.

Olynk, N. J., Tonsor, D. L., \& Wolf, C. A. (2010). Consumer willingness to pay for livestock credence attribute claim verification. Journal of Agricultural and Resource Economics, 35(2), 261-280.

Perez, C. (2014). Teen sparks outrage with photos of dead African animals. New York Post. Retrieved from http://nypost.com/2014/06/30/teen-sparks-outrage-with-photos-of-dead-african-animals

Poe, G. L., Giraud, K. L., \& Loomis, J. B. (2005). Computational methods for measuring the difference of empirical distributions. American Journal of Agricultural Economics, 87(2), 353-365.

Revelt, D., \& Train, K. (1998). Mixed logit with repeated choices: households' choices of appliance efficiency level. Review of Economics and Statistics, 80(4), 647-657.

Rothgerber, H., \& Mican, F. (2014). Childhood pet ownership, attachment to pets, and subsequent meat avoidance. The mediating role of empathy toward animals, Appetite, 79, 11-17. doi.org/10.1016/j.appet.2014.03.032.

Sackett, H. M., Shupp, R., \& Tonsor, G. (2013). Consumer perceptions of sustainable farming practices: A best-worst scenario. Agricultural and Resource Economics Review, 42(2), 275-90. doi.org/10.1017/S1068280500004378 
Scarpa, R., \& Del Giudice, T. (2004). Market segmentation via mixed logit: extra-virgin olive oil in urban Italy. Journal of Agricultural \& Food Industrial Organization, 2(1), 182-186. doi.org/10.2202/15420485.1080 .

Te Velde, H., Aarts, N. \& Van Woerkum, C. (2002). Dealing with ambivalence: farmers' and consumers' perceptions of animal welfare in livestock breeding. Journal of Agricultural and Environmental Ethics, 15(2), 203-219.

Tonsor, G. T., Olynk, N., \& Wolf, C. (2009). Consumer preferences for animal welfare attributes: The case of gestation crates. Journal of Agricultural and Applied Economics, 41(3), 713-730. doi.org/10.1017/S1074070800003175

Tonsor, G. T., Schroeder, T.C., Fox, J. A. Biere, A. (2005). European preferences for beef steak attributes. Journal of Agricultural and Resource Economics, 30(2), 367-380.

Tonsor, G. T., Wolf, C., \& McKendree. M. (2014). Research illuminates need for more beef production awareness. Beef Magazine. Retrieved from http://beefmagazine.com/animal-welfare/researchilluminates-need-more-beef-production-awareness

U.S. Census Bureau. (2014). State and country quick facts. Retrieved from http://quickfacts.census.gov/qfd/states/00000.html

U.S. Department of the Interior, U.S. Fish and Wildlife Service, and U.S. Department of Commerce, U.S. Census Bureau. (2014). 2011 National survey of fishing, hunting, and wildlife-associated recreation. Retrieved from http://www.census.gov/prod/2012pubs/fhw11-nat.pdf

United States Department of Agriculture (USDA). (2014). 2012 Census of agriculture highlights: Farm demographics. Retrieved from http://www.agcensus.usda.gov/Publications/2012/Online_Resources/Highlights/Farm_Demographics/ Highlights_Farm_Demographics.pdf

USA Today. (2014). Maine voters rejecting bear-baiting, hunting restrictions. USA Today. Retrieved from http://www.usatoday.com/story/news/politics/elections/2014/11/05/bear-baiting-hunting-restrictionsleading-in-maine/18520643/

Von Drehle, D. (2013). Cull of the Wild. Time Magazine. Retrieved from http://content.time.com/time/subscriber/article/0,33009,2158676-1,00.html 